\title{
Level Values of Robot Visual Interface Factors based on Users' Experience on Screen, Light, Face
}

\author{
Seung Eun Chung ${ }^{1}$ and Han Young Ryoo ${ }^{2 * *}$ \\ ${ }^{1,2}$ Dept. of Content Convergence, Ewha Womans University, 52, Ewhayeodae-gil, \\ Seodaemun-gu, Seoul 03760 Republic of Korea \\ ${ }^{1}$ ilovechse@ewha.ac.kr, ${ }^{2 *}$ hyryoo@ewha.ac.kr
}

\begin{abstract}
This study aims to provide the classification standards of the robot visual interface design factors that give significant differences on the user experience, and the subordinate level value derived from. In order to do so, the classification standards for screen, light, face factors of the robot visual interface were summarized by studying existing literature, and the detailed level value was summarized with the case analysis. A user survey was conducted to find out whether the summarized values from literature study and case analysis show a significant difference, and the values that indicate a difference in all aspect of functional/service experience, interactive experience, and emotional experience were eliminated. As a result of this study, 'number of light display' and 'face actualization type' were eliminated, and 'screen layout type', 'screen information expression type', 'light animation type', 'number of light color', 'Facial components materialization degree', 'face visual representation', 'facial emotion expression type' and 'facial emotion expression degree' were derived. After eliminating two from the 10 researched level classification standards, it was summarized into eight standards; after eight level values are removed, the 30 subordinate level values were combined into 22 level values.
\end{abstract}

Keywords: Robot Interface Factor and Values, Screen Interface, Light Interface, Face Interface, User Experience

\section{Introduction}

In robot design, there is a screen in the applied form of vision that is the representative sensor of information perception. Screen is used to be considered in the external appearance interface area, but it also needs to be considered in the visual interface separately from the fixed external appearance interface, from the perspective that the interaction happens through screen. Even though robot's screen is the graphic user interface (GUI), which is the traditional main interface of the digital media, as it differs from the robot screen usage experience, it is different from previous GUI design considerations. As the usage of robot has changed to interacting with Multi-Modal Interface or communicating with moving robots, there have not been many studies on the transformed screen design.

As the light factor is also importantly utilized design factor among the application form of vision, it is easy to perceive, to use and has esthetic factor and widely used in robot design. Especially, with developing LED technology, it can be manufactured in small size and enable intelligent control, and dynamic interpretation is available with various colors, brightness, dimming changes [1]. The studies on the light design provided designs

Received (December 17, 2017), Review Result (March 25, 2018), Accepted (March 30, 2018)

* Corresponding Author 
suitable for function $\mathrm{s}$ and emotions $[2,3]$; however, as they differ in the detail factors considered in design, they need to be defined.

With the appearance of social service robot, the importance of the studies on face factors in robot design became more significant. Robot face, as an expression factor that can implement various facial expression of robot, is a core interface that can directly express robot's various emotions or situations to the user. Regarding the emotion expression, in early phase, the studies on how to make the facial change more human-like and natural [4] was more important. However, as the human expectation on these expressions became more important [5], the design factors for facial expression need to be discussed from user experience perspective.

In this study, through literature study and case analysis on screen, light, face, we aims to define the level value classification standards and level values of the robot visual interface core design factors. By conducting user survey on that, the level value classification standards and detailed level values that show a difference from the user experience perspective. Also we aim to identify the robot visual interface factors that affect user experience and establish the detailed level value per service robot's visual interface design factor.

\section{Robot Visual Interface Design Factor Systematization}

\subsection{Study on Level Value Standards for Classification of Robot Visual Interface Design Factor}

In this study, in order to classify the types of screen, light, and face factors of the robot visual interface, we conducted literature and case study on the classification of core factors, discussed in previous studies.

\subsubsection{Screen Factor}

As more than $70 \%$ of the service robot are provided with a screen, according to the prior research, screen factor is very significant factor in robot's interface design. Robot's interface utilizes the screen to make facial expression and transfer information formed with image and text[6].

A text or icon provided on GUI screen is a basic design factor related to the interface usage. When looking at current robot models, the text factor of the screen determines distance from the user, depending on the screen size. Thus, each robot has different design for the text size and amount, considering the visibility. The icon factor focuses mainly on delivering information such as alarms, and it is designed for the metaphor depending on the information and robot concept. In addition, the screen factor is also used to provide external internet screen or video intactly, when connected to the external contents.

Another important key in designing screen factor is the layout. Screen is often considered as a part of the exterior design factors, because the way that screen is placed on a robot affects the overall appearance. Analyzing current service robots, the screen layout is largely divided into the case that screen is placed inside the robot and the case that screen is placed outside of the robot. First, when screen is placed inside of the robot, it's role can change depending on its placement. When screen is on the robot's head, it acts as the face of robot with facial expression and sometimes acts as information screen. When screen is on the body, it takes the role of information screen which induces interaction mainly with GUI. In case that screen is provide externally, there are module type which screen is provided with another device with screen and projector type which projects the screen on the wall. 


\subsubsection{Light Factor}

The light factor of robot is an interface element which utilizes the visual wavelength to interact. As the intelligent control is feasible to dynamically produce various color and movement changes with the developing LED technology, the light factor is used to express robot's emotion [7] or robot's status information [5]. Especially, in order to give a proper feedback to the user, it is useful to express the computing context and user context. Lee et al., (2012) divided situations expressed by the light interface into idle mode, inaction, and re-action and used the color and movement factors. The light color, switch method, and flow status are set as subordinate factors when the design was provided [5]. Baek, Suck \& Kim (2011) analyzed the subordinate factors that distinguish color and movement. The color factor is classified with the wavelength and the brightness, and the movement factor is classified into Tempo, Continuity and Rhythm. The combination of these factors are used to design. Tempo is duration of the change cycle, and Continuity shows flow from the previous change to the next change, and Rhythm captures any rule or order about the dynamic changes [8]. Using factors mentioned above, various dynamic cases with the change in color, brightness, and the movement of the color and brightness placement were identified, and these are presented with various light animation type.

Traditionally, the study on light color use and combination had been serious discussed for the home appliances [9]. Baek, Suk \& Kim (2011) found that red gives negative sense, and green and blue give positive sense, and yellow gives neutral sense. There is a multiple color use case that a function combined with appropriate color to present the information with those color senses. On the other hand, some robots use a single color or similar color palette, and these are the cases that the interaction is designed with the movement factor rather than color change. Baek, Kim \& Kim(2011) mentioned that it is important for building the product image to consider the differenciation, the consistency, and the accuracy in the light design. As using a simple color palette can intensify the differenciation of the product concept, the number of color and the arrangement is a significatn robot design factor.

In addition, the case study showed that the location or the number of the light source is immidiately perceived. When the light interface is used on the head, the facial expression elements such as eye, mouth and ear are mainly indicated. When located on the chest, the light lits when the emotion is activated or when body parts move. Dependingon the number and the location of the light source, the role and the function differ, so the study on this topic would be needed.

\subsubsection{Face Factor}

The face factor of the robot is an interface factor that transmits robot's emotion. In expressing emotions, various factors such as icons or lights are used, but usually human eyes, nose and house are used as a metaphor. So, there are studies on the factorization of the facial elements, and Kwak and Kang(2007) researched on how to increase the acceptance by lowering the robot performance expectation with disassembled facial elements, as they found out that the customer acceptance level increases as the anticipated function coincides with the actual function. In other words, whether all or part of facial elements are used is relative to the expectation on the robot functions [10]. Next, the visual representation level of facial elements is also intensively discussed. Blow et al., (2006) mentioned that human perceived robot differently based on whether robot's facial visual representation is realistic 'objective, iconic 'subjective or abstract [Blow et al.] The robot design of early phase has been developed by mimicking human appearance and behavior closely, but according to Uncanny Valle's theory, it is shown that the preference rather decreases at some point [11]. Thus, even though the level of interface implementation has been improved from the development of robot interface technology, robots with simplified expression are appearing. The simplified expression has advantages 
by amplifying of facial meaning, helping user focusing on the character it tries to express, and evoking imagination. In other words, Detail is adjusted in order to intensify Identification for Iconic level, and level of Realistic and Detail are drastically decreased to amplify the range of the imagination for Abstract level.

The studies on the emotional expression is one of the important areas in the field of facial expression. In the study of facial expression for robot's emotional expression, the types of emotions suitable for robot are first classified. Traditionally for the robot's emotional expression, Ekman's six basic emotion models: Happiness, Anger, Fear, Disgust, Sadness, Surprise are utilized, or the dimension model which is continuosly expressed in a two- or three-dimentional spaces, adding exhaustion, accepting, stem, is used $[12,13]$. Recently, however, the research on the accuracy of perception about basic emotions expressed by robots has become more important. Among six emotions, Bennett and Šabanović(2013) showed that the accuracy of perception varies according to the emotion types[14], and Jeong(2013) stated that Happiness andSadness should be given priority as an expression which robot sould express[15]. Since the emotional expression level which a user can perceive can vary on the level of robot's service or function, the designer finely consider which type of emotion needs to be dealt with.

The face actualization type is another important element considered when designing. According to Bennett and Šabanović(2013), whether robot's facial type is digital face or embodied face affects the user perception on the emotional expression. Digital face is provided from two-dimensional graphics via screen, while the embodied face is implemented in three-dimensional physical form on the appearance. In the case study, the Digital face can express various emotions by dynamically changing the facial expression, and use various visual representation methods are used such as expressing emotions with icons. As Embodied face can express emotion only through mechanical dynamic device, it seems difficult to express various emotions. Thus, there were some cases found which added color or movement of light on eyes, nose, and mouth to express emotions [6]. This shows the needs for studies on expressions using icon, lights, etc., besides facial expression changes using facial elements, as ways of expressing emotions on robot's face.

This study reviewed design factors that affect the user perception from the existing researches about screen, light, and face factor of the robot visual interface. Also, design cases are verified to find out the design factors that are significantly utilized even though they are not appeared in the existing studies. The classification factors summarized in this study are as follows.

\subsection{Level Value Summary from Case Study}

The specific level value classification standards are defined based on the classification factors derived from literature review and case studies, and the detailed level values that can include current robot trend are summarized. The interface cases of social service robots are collected and analyzed, and with the level value definition, multiple case images per one level value are summarized. 
Table 1. Robot Visual Interface Level Value Definition

\begin{tabular}{|c|c|c|c|c|}
\hline Factor & $\begin{array}{l}\text { Classification } \\
\text { Standards } \\
\end{array}$ & No. & Level Value & Level Value Definition \\
\hline \multirow{7}{*}{ Screen } & \multirow{4}{*}{$\begin{array}{l}\text { Screen layout } \\
\text { type }\end{array}$} & $1 \_1$ & $\begin{array}{l}\text { Head-integrated } \\
\text { screen }\end{array}$ & $\begin{array}{l}\text { Screen is integrated into robot's head, and } \\
\text { facial expression and information are } \\
\text { provided from single screen. }\end{array}$ \\
\hline & & $1 \_2$ & $\begin{array}{l}\text { Body-mounted } \\
\text { screen }\end{array}$ & $\begin{array}{l}\text { Screen is equipped to the robot's exterior, } \\
\text { and information screen is provided } \\
\text { separately. }\end{array}$ \\
\hline & & $1 \_3$ & $\begin{array}{l}\text { External module } \\
\text { screen }\end{array}$ & $\begin{array}{l}\text { Screen is separated from robot and provided } \\
\text { as another device, and the robot and the } \\
\text { screen are modularized to work as one level. }\end{array}$ \\
\hline & & $1 \_4$ & $\begin{array}{l}\text { External } \\
\text { projector screen }\end{array}$ & $\begin{array}{l}\text { Screen is provided as a projector type, and it } \\
\text { project the screen to the wall when needed. }\end{array}$ \\
\hline & \multirow{3}{*}{$\begin{array}{l}\text { Screen } \\
\text { information } \\
\text { display type }\end{array}$} & $2 \_1$ & Text screen & $\begin{array}{l}\text { Information is provided using simple } \\
\text { sentences }\end{array}$ \\
\hline & & $2 \_2$ & Icon screen & Information is provided using icons \\
\hline & & $2 \_3$ & $\begin{array}{l}\text { Real image } \\
\text { screen }\end{array}$ & $\begin{array}{l}\text { Information is provided with the actual } \\
\text { internet screen or the external video }\end{array}$ \\
\hline \multirow{9}{*}{ Light } & \multirow{3}{*}{$\begin{array}{l}\text { Number of } \\
\text { light display }\end{array}$} & $3 \_1$ & $\begin{array}{l}\text { One part with } \\
\text { light }\end{array}$ & $\begin{array}{l}\text { Light interaction is provided from one } \\
\text { particular part of the robot appearance }\end{array}$ \\
\hline & & $3 \_2$ & $\begin{array}{l}\text { Two parts with } \\
\text { light }\end{array}$ & $\begin{array}{l}\text { Light interaction is provided from two } \\
\text { particular parts of the robot appearance }\end{array}$ \\
\hline & & 3_3 & $\begin{array}{l}\text { More than three } \\
\text { parts with light }\end{array}$ & $\begin{array}{l}\text { Light interaction is provided from more } \\
\text { than three particular parts of the robot } \\
\text { appearance }\end{array}$ \\
\hline & \multirow{3}{*}{$\begin{array}{l}\text { Light } \\
\text { animation } \\
\text { type }\end{array}$} & 4_1 & $\begin{array}{l}\text { Color change } \\
\text { animation }\end{array}$ & Interact with the color changes \\
\hline & & 4_2 & $\begin{array}{l}\text { Brightness } \\
\text { change } \\
\text { animation }\end{array}$ & Interact with the brightness changes \\
\hline & & $4 \_3$ & $\begin{array}{l}\text { Placement } \\
\text { change } \\
\text { animation } \\
\end{array}$ & $\begin{array}{l}\text { Interact as the color or brightness of the } \\
\text { light changes the placement for a certain } \\
\text { form }\end{array}$ \\
\hline & \multirow{3}{*}{$\begin{array}{l}\text { Number of } \\
\text { light color }\end{array}$} & 5_1 & Single color & Single color of the light is used. \\
\hline & & $5 \_2$ & Similar color & $\begin{array}{l}\text { More than two similar colors of light are } \\
\text { used. }\end{array}$ \\
\hline & & $5 \_3$ & Multi-color & $\begin{array}{l}\text { More than two various colors of light are } \\
\text { used. }\end{array}$ \\
\hline \multirow{6}{*}{ Face } & \multirow{3}{*}{$\begin{array}{l}\text { Facial } \\
\text { components } \\
\text { materialization } \\
\text { degree }\end{array}$} & $6 \_1$ & $\begin{array}{l}\text { Include all facial } \\
\text { elements }\end{array}$ & $\begin{array}{l}\text { Displays all elements of eyes, nose, and } \\
\text { mouth }\end{array}$ \\
\hline & & $6 \_2$ & $\begin{array}{l}\text { Eliminate one } \\
\text { facial element }\end{array}$ & $\begin{array}{l}\text { Displays after eliminating one element } \\
\text { among eye, nose and mouth }\end{array}$ \\
\hline & & $6 \_3$ & $\begin{array}{l}\text { Eliminate two } \\
\text { facial elements }\end{array}$ & $\begin{array}{l}\text { Displays after eliminating two elements } \\
\text { among eye, nose and mouth (Displays one } \\
\text { element from eye, nose and mouth) }\end{array}$ \\
\hline & \multirow{3}{*}{$\begin{array}{l}\text { Facial visual } \\
\text { representation }\end{array}$} & 7_1 & Realistic face & Facial expression is realistically reproduced \\
\hline & & $7 \_2$ & Iconic face & $\begin{array}{l}\text { Facial expression is partially eliminated or } \\
\text { exaggerated but similarly expressed based } \\
\text { on the shape (of eye, nose and mouth) }\end{array}$ \\
\hline & & 7_3 & Abstract face & Facial expression is symbolized with \\
\hline
\end{tabular}




\begin{tabular}{|c|c|c|c|}
\hline & & & $\begin{array}{l}\text { specifically different forms or abstracted to } \\
\text { the level that it can be only recognized for } \\
\text { being at the face part. }\end{array}$ \\
\hline \multirow{2}{*}{$\begin{array}{l}\text { Face } \\
\text { actualization } \\
\text { type }\end{array}$} & 8_1 & Digital face & $\begin{array}{l}\text { Implemented to the two-dimensional } \\
\text { graphic form in a screen provided by the } \\
\text { robot }\end{array}$ \\
\hline & $8 \_2$ & Embodied face & $\begin{array}{l}\text { Implemented to the three-dimensional } \\
\text { physical form on the robot's appearance }\end{array}$ \\
\hline \multirow{3}{*}{$\begin{array}{l}\text { Facial } \\
\text { emotion } \\
\text { expression } \\
\text { type }\end{array}$} & 9_1 & $\begin{array}{l}\text { Emotion with } \\
\text { facial element }\end{array}$ & $\begin{array}{l}\text { Express emotions through the facial } \\
\text { element shape changes }\end{array}$ \\
\hline & $9 \_2$ & $\begin{array}{l}\text { Emotion with } \\
\text { icons }\end{array}$ & $\begin{array}{l}\text { Express emotions by providing icons for } \\
\text { certain emotions }\end{array}$ \\
\hline & $9 \_3$ & $\begin{array}{l}\text { Emotion with } \\
\text { light }\end{array}$ & Express emotions through the light changes \\
\hline \multirow{3}{*}{$\begin{array}{l}\text { Facial } \\
\text { emotion } \\
\text { expression } \\
\text { degree }\end{array}$} & $10 \_1$ & $\begin{array}{l}\text { Neutral } \\
\text { emotional } \\
\text { expression }\end{array}$ & Does not express any emotional change \\
\hline & $10 \_2$ & $\begin{array}{l}\text { Basic emotional } \\
\text { expression }\end{array}$ & $\begin{array}{l}\text { Express one to two basic emotions such as } \\
\text { happiness and sadness }\end{array}$ \\
\hline & $10 \_3$ & $\begin{array}{l}\text { Complex } \\
\text { emotional } \\
\text { expression }\end{array}$ & $\begin{array}{l}\text { Express various emotions such as } \\
\text { Happiness, Anger, Fear, Disgust, Sadness, } \\
\text { Surprise, and so on }\end{array}$ \\
\hline
\end{tabular}

\section{User Experience Assessment Survey on Robot Interface Design Factor}

This survey was conducted to measure the user experience on the design factor level value standards of the robot visual interface summarized from the literature and case studies previously done. The overall user experience was classified into functional/service experience, interactive experience, human-emotion experience, and for each expected item, it was measured on a seven-point Likert scale. We produced the web survey system, and total 217 men and women participated, in their 20s and 40s, who had direct or indirect experience with the service robot. The survey provided the collected multiple case images for the previously summarized level values. The level value classification standards for the 10 visual interface factors and the subordinate 30 level values are surveyed. The difference from the user experience on the level value is verified using One-Way Analysis of Variance, and the difference between each level is confirmed by Scheffé test. When there is a level value classification standard which does not show a difference in all three dimensions (functional/service experience, interactive experience, human-emotion experience), it is excluded from the classification standards. Also, when the detailed level value does not show a difference in all dimensions, they were integrated.

\subsection{User Experience Evaluation on Screen Layout Type}

The average values of 1-1. Head-integrated screen, 1-2. Body-mounted screen, 1-3. External module screen, 1-4. External projector screen that are classified with the screen layout type were compared. There was not a statistically significant difference between A)Functional/Service experience and B)Interactive experience, for the screen layout type difference. There was a statistically significant difference (p.value : $0.001<$ ) for C)Emotional experience on different screen layout types, but 'Body-mounted screen' and 'External module screen' were identified at the same level. Thus, the screen layout types were adjusted from four types to three types of Head-integrated screen, External Standalone screen (Body-mounted type and External module type) and External projector screen. 
Table 2. Level Values of Screen Layout Type Analysis Result

\begin{tabular}{|c|c|c|c|c|c|c|c|c|c|c|c|c|c|c|}
\hline UX & No & mean & group & $\mathrm{F}$ & UX & No & mean & group & F & UX & No & mean & group & $\mathrm{F}$ \\
\hline \multirow{4}{*}{ A } & 1_1 & 4.726 & $\mathrm{a}$ & \multirow{4}{*}{.72} & \multirow{4}{*}{ B } & 1_1 & 4.710 & $\mathrm{a}$ & \multirow{4}{*}{.58} & \multirow{4}{*}{$\mathrm{C}$} & 1_1 & 4.472 & $a b$ & \multirow{4}{*}{$6.47^{*}$} \\
\hline & 1_2 & 4.846 & $\mathrm{a}$ & & & 1_2 & 4.797 & $\mathrm{a}$ & & & 1_2 & 4.228 & $\mathrm{a}$ & \\
\hline & $1 \_3$ & 4.756 & $\mathrm{a}$ & & & $1 \_3$ & 4.645 & $\mathrm{a}$ & & & $1 \_3$ & 4.224 & $\mathrm{a}$ & \\
\hline & 1_4 & 4.878 & $\mathrm{a}$ & & & 1_4 & 4.682 & $\mathrm{a}$ & & & $1 \_4$ & 4.684 & $\mathrm{~b}$ & \\
\hline
\end{tabular}

*p.value : $0.001<$

\subsection{User Experience Evaluation on Screen Information Display Type}

The average values of 2-1. Text screen, 2-2. Icon screen, 2-3.Actual Image type that are classified with the screen information display type were compared. There were statistically significant differences(p.value : $0.001<$ ) on the screen information display types for A)Functional/Service experience, B)Interactive experience and C)Emotional experience, but 'Text screen' and 'Icon screen' were identified at the same level. Thus, the screen information display type, which was initially classified into 'Text screen', 'Icon screen', and 'Real image screen', is now adjusted to 'Text and Icon screen' and 'Real image screen' level.

Table 3. Level Values of Screen Information Display Type Analysis Result

\begin{tabular}{|c|c|c|c|c|c|c|c|c|c|c|c|c|c|c|}
\hline UX & No & mean & group & $\mathrm{F}$ & UX & No & mean & group & $\mathrm{F}$ & UX & No & mean & group & $\mathrm{F}$ \\
\hline \multirow{3}{*}{ A } & $2 \_1$ & 4.403 & $\mathrm{a}$ & \multirow{3}{*}{$7.69 *$} & & $2 \_1$ & 4.334 & $\mathrm{a}$ & \multirow{3}{*}{$9.58 *$} & \multirow{3}{*}{$\mathrm{C}$} & 2_1 & 4.005 & $\mathrm{a}$ & \multirow{3}{*}{$8.97 *$} \\
\hline & 2_2 & 4.392 & $\mathrm{a}$ & & & $2 \_2$ & 4.366 & $\mathrm{a}$ & & & 2_2 & 4.056 & $\mathrm{a}$ & \\
\hline & $2 \_3$ & 4.783 & $\mathrm{~b}$ & & & $2 \_3$ & 4.779 & $\mathrm{~b}$ & & & $2 \_3$ & 4.470 & $\mathrm{~b}$ & \\
\hline
\end{tabular}

*p.value : $0.001<$

\subsection{User Experience Evaluation on Number of Light Display}

The average values of 3-1. One part with light, 3-2. Two parts with light, 3-3. More than three parts with light, that are classified from the number of light display, are compared. The difference in the number of light display did not have a statistically significant difference with A)Functional/Service experience, B)Interactive experience and C)Emotional experience. Thus, the number of light display provided from the robot's exterior is eliminated from the design factor classification standards.

Table 4. Level Values of Number of Light Display Analysis Result

\begin{tabular}{|c|c|c|c|c|c|c|c|c|c|c|c|c|c|c|}
\hline UX & No & mean & group & $\mathrm{F}$ & UX & No & mean & group & F & UX & No & mean & group & F \\
\hline \multirow{3}{*}{ A } & 3_1 & 4.346 & $\mathrm{a}$ & \multirow{3}{*}{.647} & \multirow{3}{*}{ B } & 3_1 & 4.385 & $\mathrm{a}$ & \multirow{3}{*}{.039} & \multirow{3}{*}{$\mathrm{C}$} & 3_1 & 4.180 & a & \multirow{3}{*}{.027} \\
\hline & 3_2 & 4.468 & $\mathrm{a}$ & & & 3_2 & 4.387 & $\mathrm{a}$ & & & 3_2 & 4.166 & $\mathrm{a}$ & \\
\hline & 3_3 & 4.385 & $\mathrm{a}$ & & & $3 \_3$ & 4.412 & $\mathrm{a}$ & & & $3 \_3$ & 4.152 & $\mathrm{a}$ & \\
\hline
\end{tabular}

\subsection{User Experience Evaluation on Light Animation Type}

The average values of 4-1. Color change animation, 4-2. Brightness change animation, and 4-3. Placement change animation that are classified from the light animation type are compared. There was a statistically significant difference(p.value: $0.05<$ ) found between A)Functional/Service experience and B)Interactive experience, and the level values were all different. For C)Emotional experience, there was not a statistically significant difference, but as the difference between functional/service experience and interactive 
experience was confirmed, it was decided to maintain the classification with current level values.

Table 5. Level Values of Light Animation Type Analysis Result

\begin{tabular}{|c|c|c|c|c|c|c|c|c|c|c|c|c|c|c|}
\hline UX & No & mean & group & $\mathrm{F}$ & UX & No & mean & group & $\mathrm{F}$ & UX & No & mean & group & $\mathrm{F}$ \\
\hline \multirow{3}{*}{ A } & 4_1 & 4.461 & $\mathrm{a}$ & \multirow{3}{*}{$4.66 * *$} & & 4_1 & 4.505 & $\mathrm{a}$ & \multirow{3}{*}{$6.38 * *$} & & 4_1 & 4.274 & $\mathrm{a}$ & \multirow{3}{*}{2.69} \\
\hline & $4 \_2$ & 4.267 & $a b$ & & & 4_2 & 4.244 & $a b$ & & & 4_2 & 4.058 & $\mathrm{a}$ & \\
\hline & $4 \_3$ & 4.111 & $\mathrm{~b}$ & & & 4_3 & 4.101 & b & & & $4 \_3$ & 4.021 & $\mathrm{a}$ & \\
\hline
\end{tabular}

**p.value : $0.05<$

\subsection{User Experience Evaluation on Number of Light Color}

The average values of 5-1. Single color, 5-2. Similar color, and 5-3. Multi color classified by the number of light color were compared. There was not a statistically significant difference between A)Functional/Service experience and B)Interactive experience. However, a statistically significant difference(p.value: $0.001<$ ) for C)Emotional experience on the number of light color was found, and the level values were all different levels. Thus, it was decided to maintain the classification with current level values.

Table 6. Level Values of Number of Light Color Analysis Result

\begin{tabular}{|c|c|c|c|c|c|c|c|c|c|c|c|c|c|c|}
\hline UX & No & mean & group & $\mathrm{F}$ & UX & No & mean & group & $\mathrm{F}$ & UX & No & mean & group & $\mathrm{F}$ \\
\hline \multirow{3}{*}{ A } & 5_1 & 3.926 & $\mathrm{a}$ & \multirow{3}{*}{1.13} & \multirow{3}{*}{ B } & 5_1 & 3.924 & $\mathrm{a}$ & \multirow{3}{*}{.42} & \multirow{3}{*}{$\mathrm{C}$} & 6_1 & 4.846 & $\mathrm{a}$ & \multirow{3}{*}{$3.39 * *$} \\
\hline & 5_2 & 4.090 & $\mathrm{a}$ & & & 5_2 & 4.014 & $\mathrm{a}$ & & & 6_2 & 4.776 & $a b$ & \\
\hline & $5 \_3$ & 4.062 & $\mathrm{a}$ & & & $5 \_3$ & 4.018 & $\mathrm{a}$ & & & $6 \_3$ & 4.623 & $\mathrm{~b}$ & \\
\hline
\end{tabular}

**p.value : $0.05<$

\subsection{User Experience Evaluation on Facial components materialization degree}

The average values of 6-1. Include all facial elements, 6-2. Eliminate one facial element, and 6-3. Eliminate two facial elements, classified with the Facial components materialization degree, were compared. The difference on the Facial components materialization degree with A)Functional/Service experience was statistically significant (p.value: $0.05<$ ), but 'Eliminating one facial element' and 'Eliminating two facial elements' were found at the same level. For B)Interactive experience and C)Emotional experience, there was a statistically significant difference (p.value: $0.001<$ ), and it was confirmed that the level values are all in different levels. Thus, it was decided to maintain the classification with current level values.

Table 7. Level Values of Facial Components Materialization Degree Analysis Result

\begin{tabular}{|c|c|c|c|c|c|c|c|c|c|c|c|c|c|c|}
\hline UX & No & mean & group & $\mathrm{F}$ & UX & No & mean & group & $\mathrm{F}$ & UX & No & mean & group & $\mathrm{F}$ \\
\hline \multirow{3}{*}{ A } & 6_1 & 4.521 & $\mathrm{a}$ & \multirow{3}{*}{$6.39 * *$} & \multirow{3}{*}{ B } & 6_1 & 4.442 & $\mathrm{a}$ & \multirow{3}{*}{$4.62 *$} & \multirow{3}{*}{$\mathrm{C}$} & 6_1 & 4.265 & $\mathrm{a}$ & \multirow{3}{*}{$8.11 *$} \\
\hline & 6_2 & 4.544 & b & & & 6_2 & 4.517 & $a b$ & & & 6_2 & 4.512 & $a b$ & \\
\hline & 6_3 & 4.173 & $\mathrm{~b}$ & & & 6_3 & 4.177 & $\mathrm{~b}$ & & & 6_3 & 3.975 & $\mathrm{~b}$ & \\
\hline
\end{tabular}

*p.value : $0.001<, * *$ p.value : $0.05<$ 


\subsection{User Experience Evaluation on Facial Visual Representation}

The average values of 7-1. Realistic face, 7-2. Iconic face and 7-3. Abstract face that are classified with the facial visual representation level were compared. There was a statistically significant difference (p.value: $0.001<$ ) on A)Functional/Service experience and $\mathrm{B}$ )Interactive experience about the level of the facial visual representation, and it was identified that all level values are in different levels. For C)Emotional experience, there was a statistically significant difference, but 'Realistic face' and 'Iconic face' groups were identified at a same level. As the difference on all level values were confirmed from functional/service experience and interactive experience, it was decided to maintain the classification with the current level values.

Table 8. Level Values of Facial Visual Representation Analysis Result

\begin{tabular}{|c|c|c|c|c|c|c|c|c|c|c|c|c|c|c|}
\hline UX & No & mean & group & $\mathrm{F}$ & UX & No & mean & group & F & UX & No & mean & group & $\mathrm{F}$ \\
\hline \multirow{3}{*}{ A } & 7_1 & 4.353 & $\mathrm{a}$ & \multirow{3}{*}{$5.85^{* *}$} & \multirow{3}{*}{ B } & 7_1 & 4.297 & a & \multirow{3}{*}{$5.46^{* *}$} & \multirow{3}{*}{$\mathrm{C}$} & 7_1 & 4.002 & $\mathrm{a}$ & \multirow{3}{*}{$8.46^{*}$} \\
\hline & 7_2 & 4.553 & $a b$ & & & 7_2 & 4.523 & $a b$ & & & 7_2 & 4.491 & $\mathrm{a}$ & \\
\hline & 7_3 & 4.150 & $\mathrm{~b}$ & & & 7_3 & 4.141 & $\mathrm{~b}$ & & & 7_3 & 4.025 & $\mathrm{~b}$ & \\
\hline
\end{tabular}

$*$ p.value : $0.001<$, **p.value : $0.05<$

\subsection{User Experience Evaluation on Face Actualization Type}

The average values of 8-1. Digital face and 8-2. Embodied face that are classified with the face actualization type were compared. For the face actualization type, A)Functional/Service experience, B)Interactive experience and C)Emotional experience did not show a statistical significant difference. Thus, the face actualization type was eliminated from the design factor classification standards.

Table 9. Level Values of Face Actualization Type Analysis Result

\begin{tabular}{|c|c|c|c|c|c|c|c|c|c|c|c|c|c|c|}
\hline UX & No & mean & Group & $\mathrm{F}$ & UX & No & mean & group & F & UX & No & mean & group & F \\
\hline \multirow{2}{*}{ A } & 8_1 & 4.371 & $\mathrm{a}$ & \multirow{2}{*}{.54} & & 8_1 & 4.376 & $\mathrm{a}$ & \multirow{2}{*}{.25} & & 8_1 & 4.171 & $\mathrm{a}$ & \multirow{2}{*}{.70} \\
\hline & 8_2 & 4.457 & $\mathrm{a}$ & & & 8_2 & 4.318 & $\mathrm{a}$ & & & 8_2 & 4.219 & $\mathrm{a}$ & \\
\hline
\end{tabular}

\subsection{User Experience Evaluation on Facial Emotion Expression Type}

The average values of 9-1. Emotion with facial element, 9-2. Emotion with icons, and 9-3. Emotion with light that are classified by the facial emotion expression type were compared. For the facial emotion expression type, there was a statistically significant difference(p.value: $0.001<$ ) among A)Functional/Service experience and B)Interactive experience and C)Emotional experience, but it was confirmed that the Icon and the Light type are found at the same level. Thus, the facial emotion expression type, which was previously classified into 'Emotion with facial element', 'Emotion with icons' and 'Emotion with light', was adjusted into 'Emotion with facial element' and "Emotion with Other than facial element (icon or light)'.

Table 10. Level Values of Facial Emotion Expression Type Analysis Result

\begin{tabular}{|c|c|c|c|c|c|c|c|c|c|c|c|c|c|c|}
\hline UX & No & mean & group & $\mathrm{F}$ & UX & No & mean & group & $\mathrm{F}$ & UX & No & mean & group & $\mathrm{F}$ \\
\hline \multirow{3}{*}{ A } & 9_1 & 4.705 & $\mathrm{a}$ & \multirow{3}{*}{$8.99 *$} & \multirow{3}{*}{ B } & 9_1 & 4.652 & $\mathrm{a}$ & \multirow{3}{*}{$10.28 *$} & \multirow{3}{*}{$\mathrm{C}$} & 9_1 & 4.680 & $\mathrm{a}$ & \multirow{3}{*}{$18.31 *$} \\
\hline & 9_2 & 4.622 & $\mathrm{~b}$ & & & 9_2 & 4.553 & $\mathrm{~b}$ & & & 9_2 & 4.673 & $\mathrm{~b}$ & \\
\hline & 9_3 & 4.230 & $\mathrm{~b}$ & & & 9_3 & 4.148 & $\mathrm{~b}$ & & & $9 \_3$ & 3.995 & $\mathrm{~b}$ & \\
\hline
\end{tabular}

*p.value : $0.001<$ 


\subsection{User Experience Evaluation on Facial Emotion Expression Degree}

The average values of 10-1. Neutral emotional expression, 10-2. Basic emotional expression, and 10-3. Complex emotional expression that were classified with the degree of the facial emotional expression were compared. For A)Functional/Service experience and B)Interactive experience, a statistically significant difference(p.value: $0.001<$ ) was found, but 'Neutral emotional expression' and 'Basic emotional expression' were found at the same level. There was a statistically significant difference(p.value: $0.001<$ ) with C)Emotional experience, the level values were confirmed to be at all different levels. Thus, it was decided to maintain the classification of the current level value.

\section{Table 11. Level Values of Facial Emotion Expression Degree Analysis} Result

\begin{tabular}{|c|c|c|c|c|c|c|c|c|c|c|c|c|c|c|}
\hline UX & No & mean & group & $\mathrm{F}$ & UX & No & mean & group & $\mathrm{F}$ & UX & No & mean & group & $\mathrm{F}$ \\
\hline \multirow{3}{*}{ A } & 10_1 & 4.039 & $\mathrm{a}$ & \multirow{3}{*}{$21.70 *$} & \multirow{3}{*}{ B } & 10_1 & 4.035 & $\mathrm{a}$ & \multirow{3}{*}{$10.28 *$} & \multirow{3}{*}{$\mathrm{C}$} & 10_1 & 3.634 & $\mathrm{a}$ & \multirow{3}{*}{$29.87 *$} \\
\hline & 10_2 & 4.263 & $\mathrm{a}$ & & & 10_2 & 4.270 & $\mathrm{a}$ & & & 10_2 & 3.136 & b & \\
\hline & $10 \_3$ & 4.615 & $\mathrm{~b}$ & & & 10_3 & 4.581 & $\mathrm{~b}$ & & & 10_3 & 4.652 & $\mathrm{c}$ & \\
\hline
\end{tabular}

*p.value : $0.001<$

\section{Conclusion}

In this study, the classification standards for level values of the core design factors of the visual interface through the research of the existing literature and level value examples were summarized through the case studies. Then, we investigated whether the detailed level values of the summarized visual interface factors give a significant difference to the user experience perspective and aimed to provide the design factors and the level values that affect the user experience.

The user experience is categorized into functional/service experience, interactive experience, and human emotional experience and investigated. Regarding the survey result, the classification standard which does not show any difference in the user experience is eliminated, and the level value classification which shows at least one difference among three dimensions is accepted. Accordingly, as significant classification standards about the visual interface design factor for measuring the overall user experience, 'number of light display', 'face actualization type' were eliminated, and 'screen layout type', 'screen information expression type', 'light animation type', 'number of light color', 'Facial components materialization degree', 'facial visual representation', 'facial emotion expression type' and 'facial emotion expression degree' were utilized. Thus, among the 10 level value classification standards, two standards were eliminated, resulting eight standards at the end.

In the survey result of the detailed level values, there are some cases that only certain level values are combined. First, 'body-mounted screen' and 'external module screen' did not show any difference in 'screen layout type'. For the case of 'body-mounted screen', even though the screen is provided integrally with the exterior of the robot body, the perception on the screen, which is provided for providing information, seems to be affected. Next, in 'screen information display type', 'Text screen' and 'Icon screen' did not show a difference. 'Text screen' or 'Icon screen' are adjusted depending on the robot's concept or size, so there is a characteristic that contents and amounts of the provided information are refined by the robot service provider. In case of 'Real image screen', as internet screen and external videos are provided intact, it has a difference that the user can obtain information without distinction from other media. From this aspect, the evaluation of 'Text screen' and 'Icon screen' is interpreted as the same. Finally, for 'facial emotion expression type', ' Emotion with icons' and 'Emotion with light' did not show a difference. 
Generally, human emotion expression is expressed using the facial expression changes, but for robot's case, there are cases that the facial elements are not used depending on the applied robot technology and the design concept. There are some cases that factors such as icon or light are used to express emotion, and user considered these non-facial element as an extra element, so evaluations on 'Emotion with icons' and 'Emotion with light' are interpreted to be the same. Thus, as eight level values are eliminated, the surveyed 30 subordinate level values are summarized into 22 .

This study was done as a base study to systemize the robot interface design factors from the perspective of user experience. The result of this study will be utilized as a design library that can be used for the service robot design which is based on user expectation experience survey on each service. Even though it was not specifically stated as a result of this study, the design factor classification standards that show a difference in a specific dimension help understanding the dimension of experience expected by the user for certain deign factors. 'Screen layout type', 'number of light color' and 'facial emotion expression degree' affected the emotional experience more than functional/service experience and interactive experience. On the other hand, 'light animation type' affected functional/interactive experience more than the emotional experience. Through the research, the dimension of the experience that user expects, for some design factors, was understood, and the designer learned the design factors that need to be used for the targeted user experience design. The focus in this study was robot's visual interface design factor, and in the future, a research on the auditory interface and behavior interface design factor will be conducted.

\section{Acknowledgments}

This research was supported by Basic Science Research Program through the National Research Foundation of Korea (NRF) funded by the Ministry of Education (No.2017R1A6A3A11031044).

This paper is a revised and expanded version of a paper entitled "Visual Interface Factor Research for Robot Design" presented at The 10th International Conference on Advanced Science and Technology, Ho Chi Minh, Vietnam, (2018) February 1-3.

\section{References}

[1] S. Y. Nam, M. S. Park and J. K. Kang, "LED technology and application of green energy", Sunghakdang press, (2010).

[2] B. Baek, J. Kim and M. Kim, "An Exploratory Study on the Influence of Light Feature Design on Building Brand Image: With the Case of Macbook", Proceedings of HCI Korea, (2011) January.

[3] B. N. Baek, H. J. Suk and H. S. Kim, "Context Information Representation Applying Light Attributes Representation of Abstracted Context Information Using LED”, Archives of Design Research, vol. 25, no. 1, (2012), pp. 207-218.

[4] M. J. Jung, H. S. Lee and D. H. Kim, "Emotion and Personality of Robots: from Recognition to Expressions of Facial Expressions", Korea robotics society review, vol. 25, no. 1, (2005), pp. 68-76.

[5] H. Lee, Y. Jung, J. Rhim and M Kim, "State Feedback Design for the Future Robotic Computer", Proceedings of HCI Korea, (2012) January

[6] S. E. Chung and H. Y. Ryoo, "Visual Interface Factor Research for Robot Design", Proceedings of The 10th International Conference on Advanced Science and Technology, Ho Chi Minh, Vietnam, (2018) February 1-3.

[7] M. G. Kim, H. S. Lee, J. W. Park, S. H. Jo and M. J. Chung, "Color and Blinking Control to Support Facial Expression of Robot for Emotional Intensity”, Proceedings of HCI Korea, (2008) January.

[8] B. N. Baek, H. J. Suk and M. S. Kim, "Context information representation applying light attributesrepresentation of abstracted context information using LED”, Korean Journal of Design Studies, vol. 25, no. 1, (2012), pp. 207-218.

[9] J. Kim and Y. Park, "Products Used in LED Color Analysis - Consumer Product centric", Proceedings of Korea Society of Color studies, (2012) November.

[10] S. S. Kwak and D. Kang, "FacePartBot: The Interactive Face Components", Proceedings of the Companion of the 2017 ACM/IEEE International Conference on Human-Robot Interaction, (2017) March. 
[11] M. Mori, “The Uncanny Valley”, Energy, vol. 7, no. 4, (1970), pp. 33-35.

[12] H. Miwa, T. Okuchi, K. Itoh, H. Takanobu and A. Takanishi, "A new mental model for humanoid robots for human friendly communication", Proceedings of the 2003 IEEE Int. Conf. on Robotics and Automation, (2003) September.

[13] D. H. Kim, H. S. Lee and M. J. Chung, "Biologically inspired models and hardware for emotive facial expressions", RO-MAN2005, proceedings of ROMAN 2005, IEEE International Workshop, (2005) August.

[14] C. Bennett and S. Šabanovic, "Perceptions of affective expression in a minimalist robotic face", proceedings of 2013 8th ACM/IEEE International Conference, (2013) March.

[15] S. Jeong, "Designing facial expressions of an educational assistant robot by contextual methods", Archives of Design Research, vol. 26, no. 2, (2013), pp. 409-435.

\section{Authors}

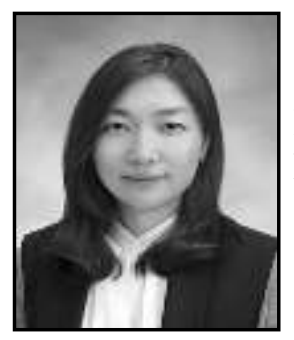

Seung Eun Chung, is a research professor in the Dept. of Content Convergence at Ewha Womans University. She received Ph.D in Media Design from the Division of Digital media at Ewha Womans University. Her research areas are user experience design, graphic user interface design, and so on.

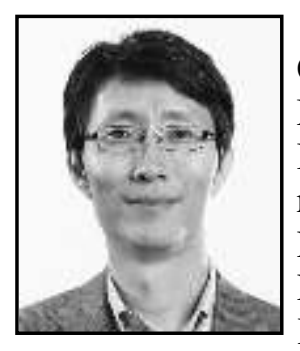

Han Young Ryoo, is a professor in the Dept. of Content Convergence at Ewha Womans University. He received B.S. \& M.F.A. degrees in Industrial Design from KAIST (Korea Advanced Institute of Science and Technology) \& Kookmin University respectively, and D.Sc. in Interactive Multimedia from the Department of Computer Science at George Washington University. $\mathrm{He}$ has also worked as an editor of Journal of the HCI Society of Korea. His research areas are user experience design, user interface design, usability evaluation, and so on. 